\title{
Detection of illicit drugs in urine in the Division of Neonatology Hospital Molas in La Pampa
}

\author{
Marina Villarreal, M.D. ${ }^{a}$ and Silvina Ré, M.D. ${ }^{a}$
}

\begin{abstract}
There are few studies on the use of illicit drugs during pregnancy with a variable prevalence depending on the year, maternal age, region and diagnostic methods. Mothers' and newborn infants' urine samples were tested for illegal drugs in cases where the mother reported consumption, lack of antenatal care and neonatal signs and symptoms, from 2009 to 2011. A rapid strip test for simultaneous qualitative detection of multiple drugs and metabolites in urine was used. In 19 out of 39 (49\%) cases in which urine samples were collected, an illicit drug was detected in the mother and/or the newborn infant. Cocaine was the most frequently detected drug. There was a high coexistence of social and familiar risk factors, smoking ( $84 \%$ ) and alcohol consumption (47\%).

Key words: pregnancy, detection, illicit drugs, neonatology, urine.
\end{abstract}

http:/ /dx.doi.org/10.5546/aap.2013.232

\section{INTRODUCTION}

As a consequence of globalization, illicit drug trafficking has spread to almost every country in the world. ${ }^{1}$

Given that the rate of drug use is the highest among adolescents and young adults, i.e. individuals of childbearing potential, this problem involves both pregnant women and their infants. $^{2-5}$

The consequences of illicit drug use during pregnancy are under discussion due to the high rate of confounding factors, such as polydrug use. ${ }^{6,7}$

Studies on this matter are scarce and difficult to compare, and they depend on the year, the region and the diagnostic methods used. . $^{3,48}$

In neonatology, so as to prevent discriminatory practices, illicit drug detection tests are recommended when mothers and newborn infants have predefined medical criteria. ${ }^{9}$

a. Division of Neonatology, Hospital "Dr. Lucio Molas". Santa Rosa, La Pampa. Argentina.

Marina Villarreal, M.D.: marvillarreal@cpenet.com.ar.

Conflict of interest: none.

Received: 6-25-2012

Accepted: 2-16-2013

\section{OBJECTIVES}

To submit the results of illicit drug screening practices in mother-newborn infant dyads at the Division of Neonatology of the Hospital Molas in La Pampa, Argentina, and their associated factors.

\section{POPULATION AND METHODS}

Medical records of mothers and newborn infants were retrospectively reviewed to investigate the presence of illicit drugs in urine in the 2009-2011 period.

An illicit drug was defined as any illegal drug in Argentina, or a substance of abuse that, even though it should be used under medical prescription, it is taken without one. ${ }^{9}$

Samples were requested as per medical judgment (Table 1) and collected by the mother, or in her presence if mother and newborn infant were hospitalized together. Samples from the newborn infant (urine bag collection) and the mother (spontaneous sample collected in a bottle) were obtained as soon as possible after birth.

Method: Acon Laboratories (USA) rapid strip test for simultaneous qualitative detection of drugs or drug metabolites: amphetamines, barbiturates, benzodiazepines, marihuana, cocaine, methadone, methamphetamines, opioids, and phencyclidine.

TABLE 1. Medical criteria for requesting urine illicit drug screening to mothers and newborn infants in the Division of Neonatology*

1. Statement reporting current or past drug use.

2. Altered mental status in the mother.

3. Lack of antenatal care.

4. Unexplained central nervous system complications in the newborn infant.

5. Symptoms compatible with drug withdrawal in the newborn infant.

6. Changes in neonatal behavior.

*Adapted from Sample guideline for newborn drug testing. University of Arkansas for Medical Sciences, ANGELS Neonatal Guidelines. ${ }^{9}$ 
Test strips were obtained through standard hospital procurement mechanisms.

Data were recorded in Excel 2003 and analyzed with GraphPad Prism 5. Quantitative outcome measures are expressed as average and standard deviation, or as median and confidence intervals, as appropriate. Categorical outcome measures are expressed as proportions.

The study was approved by the Research Committee and the Ethics Committee of the Hospital "Dr. Lucio Molas".

\section{RESULTS}

A total of 47 mother-newborn infant dyads were included. In 19 out of $39(49 \%)$ cases in whom urine samples were collected, an illegal drug was detected in either the mother or the newborn infant (Figure 1).
Criteria for requesting urine samples included: maternal self-report of drug use in 11 cases (indicated in the patient record in 7 cases and reported by the mother after birth in 4 cases), lack of antenatal care in 6 cases, and neonatal signs and symptoms in 6 cases. More than one criterion was present in 4 mother-newborn infant dyads.

Out of these 19 dyads, a sample was obtained from the mother and the newborn infant in 15 $(84 \%)$ cases, and from either the mother or the newborn infant in the rest of the cases due to technical difficulties. A total of 34 samples were collected. Drugs detected are detailed in Table 2.

Only one illicit drug was detected in 12 of the 19 cases (63\%), 2 drugs were found in 5, and 3 drugs, in 2. The most common association was cocaine and marihuana.

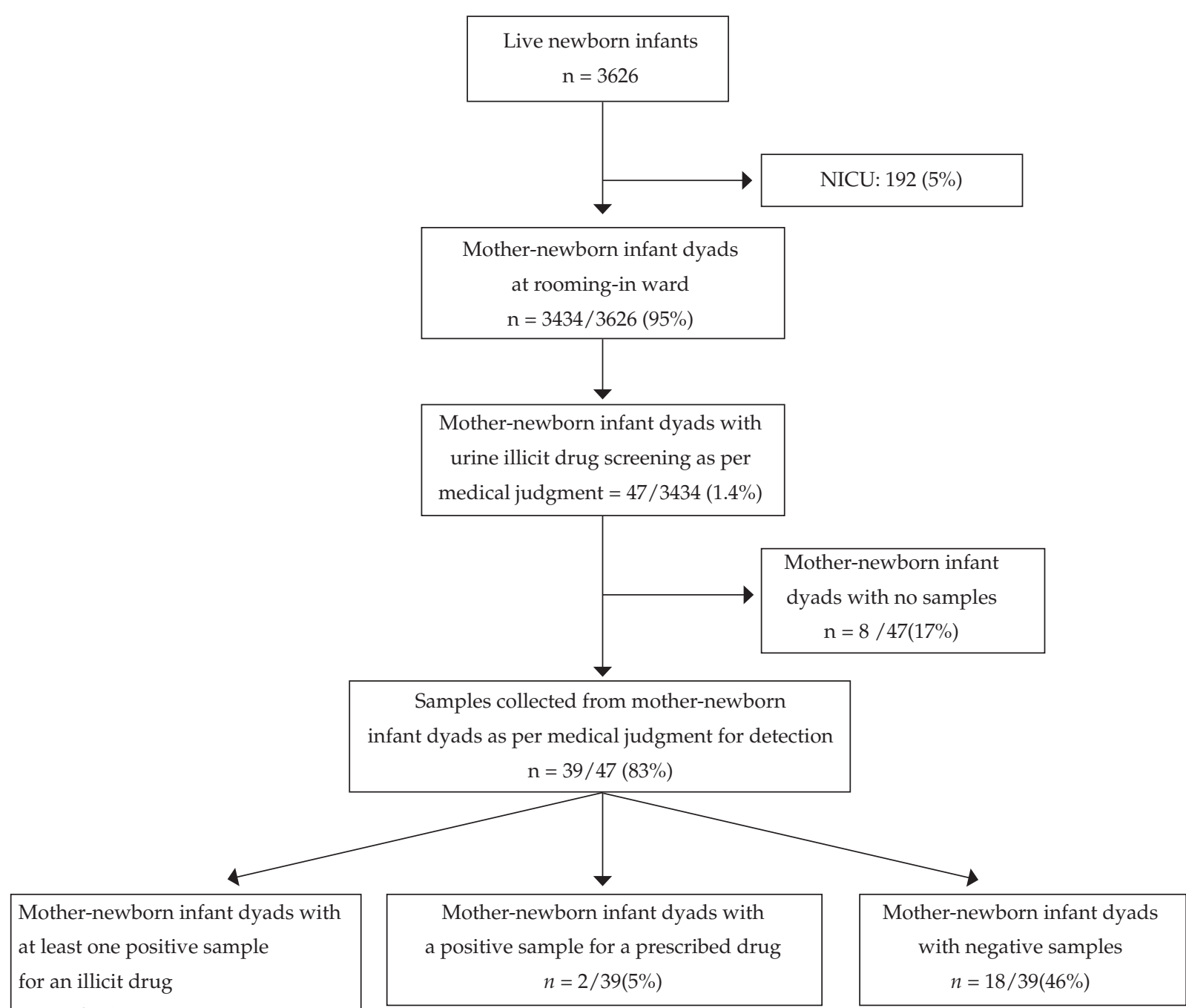




\section{Maternal Data}

Of 19 mothers, 18 (95\%) lived in Santa Rosa, the capital city of La Pampa. Their median age was 21 years old (95\% CI: 19.2-23.53). Their median number of gestations was 2 (95\% CI: 1.893.26).

Of the 19 women, 10 had a partner, and 8 of them were illicit drug users. One of the women was living with addicted parents.

Twelve of the $19(63 \%)$ cases had a history of violence prior to pregnancy leading to medical consultation.

Sixteen out of $19(84 \%)$ women smoked during pregnancy, with a median of 15 cigarettes / day (95\% CI: $10.24-17.49)$. Nine (47\%) of the 19 women used alcohol.

\section{Newborn Infant Data}

The median gestational age was 39 weeks (95\% CI: 37.69-39.68); 1 infant was born preterm at
31 weeks, with an adequate weight. The median birth weight was $3170 \mathrm{~g}$ (95\% CI: 2731-3321); 3 $(16 \%)$ of the 19 newborn infants were small for their gestational age. The Apgar score at 1 minute was 3; all remaining scores were over 7 .

Neonatal clinical signs are presented in Table 3. Two newborn infants were admitted to the NICU due to respiratory distress. The median hospital length of stay was 4 days (95\% CI: 2.69-13.20).

When the positive urine test result was reported, mothers that had previously not reported using illicit drugs, did recognize that they had used them.

In all cases, breastfeeding was interrupted, a consultation was made with the Mental Health Department, and a report was submitted to the Undersecretariat of Addiction Issues of the Ministry of Health of La Pampa. One of the cases was taken to court.

The Mental Health Department conducted at

TABLE 2. Illicit drugs detected in urine samples $(n=34)$ in each member of mother-newborn infant dyads and the time samples were obtained.

\begin{tabular}{lcccc} 
Dyad no. & Results of maternal samples $(n=17)$ & H & Results of neonatal samples $(n=17)$ & H \\
\hline 1 & Cocaine and marihuana & 9 & Cocaine and marihuana & 9 \\
2 & Marihuana & 2 & Negative & 4 \\
3 & Negative & 24 & Phencyclidine & 8 \\
4 & Cocaine and benzodiazepine & 1 & Cocaine and phencyclidine & 7 \\
5 & No sample & -- & Cocaine & 2 \\
6 & Phencyclidine & 4 & Phencyclidine & 2 \\
7 & Cocaine and benzodiazepine & 1 & Cocaine & 6 \\
8 & Cocaine and marihuana & 2 & Phencyclidine & 7 \\
9 & No sample & -- & Cocaine & 5 \\
10 & Marihuana & 3 & Marihuana & 5 \\
11 & Cocaine and marihuana & 2 & Cocaine & 6 \\
12 & Cocaine & 4 & Cocaine & 8 \\
13 & Cocaine and marihuana & 4 & Cocaine & 9 \\
14 & Cocaine & 10 & Cocaine & 15 \\
15 & Phencyclidine & 7 & Negative & 30 \\
16 & Cocaine & 5 & Negative & 48 \\
17 & Marihuana & Negative & 6 \\
18 & Marihuana & No sample & -- \\
19 & Cocaine and marihuana & No sample & -- \\
\hline
\end{tabular}

H: hours after birth. 
least one interview with each mother and offered them the possibility of continuing treatment at a health facility closer to their home.

\section{DISCUSSION}

In 2009 an internal consensus was established at the Neonatology Division to screen illicit drugs as per medical judgment so as to avoid unnecessary tests or treatments and to provide specific support to the families. ${ }^{9}$

The urine screening test was selected because it is a simple, non invasive test with a rapid result (15 to 20 minutes after sample collection).

The disadvantages of this method are its low sensitivity $(37 \%)$ and that it only detects the presence of drugs used in the past 72 hours. $^{9}$ Particularly, in the case of cocaine, it only detects high levels. ${ }^{3}$ Taking such limitations into consideration, the cases presented here account for only a small percentage of cases of illicit drug use during pregnancy in our population.

In relation to the medical screening criteria, maternal self-report nearly always is less than $50 \%$ of actual use. ${ }^{4,8}$ In our study, $58 \%$ of mothers testing positive admitted that they had used drugs; this was the main criterion for requesting urine samples. It is important the case history is repeated because even though most mothers reported using drugs during the antenatal care period, $21 \%$ did so after giving birth.

The second criterion in place for requesting urine samples was the lack of antenatal care (31\% of cases), similar to the $37 \%$ found in a Spanish trial. $^{3}$

The fact that the study was retrospective is a restraint. It was not possible to know the reason why screening tests had not been done in 8 mother-newborn infant dyads.

Negative results were not analyzed. Such results may have been due to method limitations, an actual lack of drug use or to use long before giving birth.

Positive laboratory tests for urine illicit drug screening should be evaluated in the clinical setting, and those which are difficult to interpret or not recognized by the patient should be confirmed with other tests. ${ }^{3,10}$ The detection of certain drugs or metabolites may be due to illicit use, but also to a medical indication, or even to the use of certain food seasonings or the use of pain relievers, allergy medicines and cough syrup. . $^{11,12}$

In the 19 mother-newborn infant dyads with positive drug screening tests, a larger number of positive results were found in maternal samples versus neonatal samples (see Table 2), which may be related to a longer delay in sample collection. From a technical standpoint, it is not easy to obtain a sample from a newborn infant, whose positive result is more likely in the first urine pass. ${ }^{11}$ The only dyad in which the newborn infant tested positive and the mother negative was in the case where the mother's sample had been collected 24 hours after birth.

Cocaine was the most common finding and, as described by other authors, it was almost always associated with the use of another illicit substance. ${ }^{3,4}$

Neonatal signs were related to the detection of more than one drug in urine, also as described in a Mexican study. ${ }^{13}$ The percentage of infants born small for gestational age was $16 \%$, lower than the $40 \%$ observed in Costa Rica. ${ }^{3}$ No malformations were found, possibly because the sample size was small.

Alcohol or tobacco use is a known risk factor for the use of illicit substances. ${ }^{14,15}$ In a Colombian study, pregnant women with positive cocaine

TABLE 3. Clinical signs in newborn infants in relation to the illicit drug detected in urine $(n=6)$.

\begin{tabular}{|c|c|c|}
\hline Case & Clinical signs & Drug(s) detected(s) \\
\hline 1 & Tremor and hypotonicity & Cocaine and marihuana \\
\hline 2 & Tachypnea and feeding difficulty & Cocaine and benzodiazepine \\
\hline 3 & Hypotonicity and feeding difficulty & Cocaine, marihuana and phencyclidine \\
\hline 4 & Irritability & Cocaine and marihuana \\
\hline 5 & Hyporesponsiveness and feeding difficulty & Marihuana \\
\hline 6 & Tachypnea and feeding difficulty & Cocaine and marihuana \\
\hline
\end{tabular}


results in urine also showed a high rate of smoking (84\%) and alcohol use (63\%); figures which are similar to those found in our study. ${ }^{6}$

One of the strengths of this study is that it enables to confirm the existence of this problem, to establish which drugs are circulating among this population, and to estimate a minimum number of vacancies in treatment programs that should be created in La Pampa to improve the availability of treatments.

\section{Acknowledgments}

To Doctors Natalia Fatala and Carlota Braceras.

\section{REFERENCES}

1. Buss PM. Globalización, Pobreza y Salud. Premio Conferencia Hugh Rodman Leavell. Salud colectiva 2006;2(3):281-97.

2. Observatorio Argentino de Drogas. Cuarta Encuesta Nacional a estudiantes de enseñanza media argentina 2009. Secretaría Nacional de programación para la prevención de la drogadicción y de la lucha contra el narcotráfico. [Accessed on: January 142012 ]. Available at: http:/ / www. observatorio.gov.ar/informes/provinciales/Ciudad_de_ Buenos_Aires-ESCOLARES2009_v2.pdf.

3. MardomingoM,SánchezG,Málaga GuerreroS, Cuadrillero Quesada C, et al. Consumo de drogas durante el embarazo y morbilidad neonatal: cambios epidemiológicos en los últimos 10 años. An Pediatr 2003;58(6):574-9.

4. Lester BM, Elsohly M, Wright LL, Smeriglio VL, et al. The maternal lifestyle study: drug use by meconium toxicology and maternal-self report. Pediatrics 2001;107(2):309-17.

5. Suárez A, Peirano A, González I, Odierna E., et al. Investigación de cocaína y marihuana en meconio de neonatos atendidos en un hospital público. Primera experiencia realizada en la ciudad de Córdoba, Argentina. Acta Toxicol Argent 2009;17(2):41-7.

6. Roa JA, Echandía CA, Rodríguez MV, Lozano MI, et al. Rastreo de cocaína en orina de recién nacidos hijos de madres consumidoras. Colombia Médica 2003;34(1):24-30.

7. Mishuro SS, Chalem E, Moraes Barros M, Guinsburg R, et al. Teenage pregnancy: use of drugs in the third trimester and prevalence of psychiatric disorders. Rev Bras Psiquiatr Epub 2006;28(2):122-5.

8. Bessa MA, Mitsuhiro SS, Chalem E, Barros MM, et al. Underreporting of use of cocaine and marijuana during the third trimester of gestation among pregnant adolescents. Addict Behav 2010;35(3):266-9.

9. FarstK, Valentine JL, Whit Hall R. Drug Testing for Newborn Exposure to Illicit Substances in Pregnancy: Pitfalls and Pearls. Int J Pediatr 2011;2011:951616.

10. Friguls B, Joya X, Garcia-Serra J, Gómez-Culebra M, et al. Assessment of exposure to drugs of abuse during pregnancy by hair analysis in a Mediterranean island. Addiction 2012;107(8):1471-9.

11. Wolff K, Farrell M, Marsden J, Monteiro MG, et al. A review of biological indicators of illicit drug use, practical considerations and clinical usefulness. Addiction 1999;94(9):1279-98.

12. MartínezSánchez L. Detección de fenciclidina en el cribado toxicológico en orina: un falso positivo peligroso. Carta al editor. An Pediatr (Barc) 2011;74(6):418-33.

13. Goel N, Beasley D, Rajkumar V, Banerjee S. Perinatal outcome of illicit substance abuse in pregnancycomparative and temporary socio-clinical profile in the UK. Eur J Pediatr 2011;170(2):199-205.

14. Gutiérrez Mena RM, Navarrete MP, Corvalán VS, Bedregal GP. Drogadicción embriofetal por abuso de pasta base de cocaína durante el embarazo. Rev Méd Chile 2000;128(10):1093-100.

15. Gutiérrez-Padilla JA, González-Garrido AA, GómezVelázquez FR, Torre-Gutiérrez M, et al. Hijos de madres adictas con síndrome de abstinencia en Terapia Intensiva Neonatal Bol Med Hosp Infant Mex 2008;65:276-81. 